\title{
Keefektifan Model Pembelajaran Cooperative Integrated Reading And Composition (CIRC) Terhadap Kemampuan Membaca Siswa
}

\author{
*Weni Murtiningrum¹, Mei Fita Asri Untari², Ahmad Nashir Tsalatsa ${ }^{3}$ \\ 1,2,3 Pendidikan Guru Sekolah Dasar, Fakultas Ilmu Pendidikan,Universitas PGRI Semarang, Indonesia
}

\section{A R T I C L E I N F O \\ Article history: \\ Received 10 November 2018 \\ Received in revised form 09 December 2018 \\ Accepted 15 January 2019 \\ Available online 25 \\ February 2019}

Kata Kunci:
Efektifitas, CIRC,
kemampuan membaca
siswa
Keywords:
Efectivity, CIRC, reading
ability

\begin{abstract}
A B S T R A K
Rendahnya kemampuan memebaca siswa dengan menggunakan metode pembelajaran konvensional. Peneliti ini bertujuan untuk mengidentifikasi efektif atau tidaknya model pembelajaran Cooperative Integrated Reading and Composition (CIRC) terhadap kemampuan membaca siswa kelas IV SD Negeri 1 Ngalian Kabupaten Wonosobo. Penelitian ini merupakan penelitian ekperimen jenis kuantitatif. Penelitian ini menggunakan One Group Pretest-Posttest Design. Populasi dalam penelitian ini adalah seluruh peserta didik kelas IV SD berjumlah 24 siswa tahun ajaran 2018/2019. Intrumen yang digunakan adalah wawancara, dokumentasi dan tes. Analisis Data menggunakan Teknis analisis data peneliti menggunakan uji normalitas dan uji hipotesis (uji-t). Uji normalitas digunakan untuk mengetahui kelas tersebut berdistribusi normal atau tidak. Uji hipotesis menggunakan uji t-test. Hasil penelitian yang dilakukan dapat disimpulkan bahwa model pembelajaran Cooperative Integrated Reading and Composition (CIRC) efektif terhadap kemampuan membaca kelas IV SD. Hal ini dapat dilihat dari rata-rata hasil postest lebih tinggi dari hasil pretest selain itu diperkuat dengan hasil perhitungan uji t diperoleh thitung untuk hasil belajar sebesar 17,68 dan dan ttabel sebesar 2,021 karena thitung
\end{abstract} $(17,68)>$ ttabel $(2,021)$ maka hal ini menunjukkan bahwa uji t hasil belajar signifikan.

\begin{abstract}
A B S T R A C T
This researcher aims to identify whether or not the Cooperative Integrated Reading and Composition (CIRC) learning model is effective against the reading ability of Grade IV students at SD Negeri 1 Ngalian, Wonosobo Regency. This research is a quantitative type of research. This study uses One Group Pretest-Posttest Design. The population in this study were all fourth grade students of SD Negeri 1 Ngalian Wonosobo Regency totaling 24 students in the 2018/2019 academic year. The instruments used are (1) interviews, Documentation and test. Data Analysis using Technical data analysis researchers used the normality test and hypothesis testing (t-test). The normality test is used to find out whether the class is normally distributed or not. Hypothesis testing uses the $t$-test. The results of the research conducted can be concluded that the Cooperative Integrated Reading and Composition (CIRC) learning model is effective against reading ability in grade IV of SD Negeri 1 Ngalian, Wonosobo Regency. This can be seen from the average posttest results higher than the pretest results other than that it is reinforced by the results of $t$-test calculations obtained by tcount for learning outcomes of 17,68 and t table of 2,021 because of tcount $(17,68)>t$ table $(2,021)$ then this shows that $t$-test results are significant.
\end{abstract}




\section{Pendahuluan}

Pembelajaran Bahasa Indonesia perlu dikemas dengan baik untuk meningkatkan aktivitas belajar dan kemampuan membaca siswa. Melalui observasi awal di SD Negeri 1 Ngalian Kabupaten Wonosobo pada kelas IV tahun pelajaran 2018/2019 semester I diperoleh data yang menunjukkan bahwa proses pembelajaran masih berlangsung secara konvensional dan nilai siswa masih dibawah ketuntasan minimal. Hal itu disebabkan dalam pembelajaran guru belum menggunakan model pembelajaran yang sesuai. Berdasarkan hasil wawancara yang disampaikan oleh Ibu Kasih Widiastuti S.Pd.SD selaku wali kelas IV SD Negeri 1 Ngalian Kabupaten Wonososbo menyatakan bahwa kendala yang dialami pada saat pembelajaran yaitu kurangnya inovasi pada model pembelajaran yang digunakan dalam pembelajaran tematik. Sehingga siswa kurang tertarik dan kurang memperhatikan pembelajaran yang disampaikan oleh guru(Shoimin, 2015). Oleh karena itu, guru perlu menggunakan model pembelajaran yang inovatif dan dapat menarik perhatian siswa. Berdasarkan data awal hasil belajar yang diperoleh siswa masih belum mencapai kriteria ketuntasan minimal yang dibuat standar minimal guru kelas IV yaitu nilai KKM 70 dan ketuntasan klasikal 75\%. Ketuntasan belajar yang dicapai siswa baru didapat oleh 9 siswa dari jumlah 24 siswa.

Berdasarkan data awal, belum tuntasnya atau belum tercapainya aktivitas dan hasil belajar siswa disebabkan oleh pembelajaran yang digunakan guru masih menggunakan metode konvensional. Oleh karena itu diperlukan metode atau model pembelajaran yang sesuai dengan materi yang diajarkan tema 4 subtema 1. Diharapkan dengan model pembelajaran yang sesuai tersebut aktivitas dan hasil belajar siswa akan lebih meningkat. Alternatif metode atau model pembelajaran yang dapat peneliti berikan adalah dengan model pembelajaran Cooperative Integrated Reading and Composition (CIRC)(Sudjana, 2005).Penerapan model pembelajaran Cooperative Integrated Reading and Composition (CIRC) dalam pembelajaran tematik di SD sesuai dengan karakteristik siswa. Dengan menggunakan model pembelajaran kooperatif tipe Cooperative Integrated Reading And Composition (CIRC) ini, siswa akan menemukan pengetahuan baru secara perlahan melalui pengalaman siswa yang telah dilakukannya. Dalam pembelajaran siswa harus menemukan sendiri pengetahuan-pengetahuan dan dapat mengecek informasi baru yang didapat dengan aturan-aturan lama yang berlaku. Agar siswa dapat benar-benar memahami dan dapat menerapkan pengetahuan, mereka harus belajar untuk menganalisis suatu masalah dan menemukan penyelesaian apa yang tepat(Huda, 2013).

Membaca cepat adalah kegiatan membaca dengan mengandalkan kecepatan gerak mata dalam melihat dan memperhatikan bahan tertulis yang dibacanya, dengan tujuan untuk mendapatkan informasi secara cepat menurut Turahmat (2010:41). Tujuan utama dalam membaca cepat bukan untuk mencari kata dan gambar secepat mungkin namun untuk mengidentifikasi dan dapat memahami makna dari suatu bacaan. Apabila waktu yang digunakan semakin sedikit dalam membaca dan tingkat pemahamannya semakin meningkat maka dapat dikatakan bahwa tingkat kemampuan membaca orang tersebut semakin meningkat(Rahim, 2005). Menurut Hernowo dalam Aizid (2011: 40), membaca cepat adalah suatu kegiatan merespons lambang-lambang cetak atau lambang tulis dengan perhatian yang tepat dan cepat, Membaca cepat adalah kemampuan dengan kecepatan yang sama. Menurutnya, kecepatan membaca itu harus fleksibel. Menurut Soedarso (2005:13), kecepatan membaca itu tidak harus selalu sama, tetapi ada kalanya diperlambat karena bahan-bahan dan tujuan Anda dalam membaca yang berbeda-beda. Membaca cepat sebagai sebuah kegiatan membaca dengan kecepatan tinggi, yang mencakup hampir seluruh materi bacaan di baca. Menurut Listiyanto dalam Aizid (2011:41), membaca cepat termasuk aktivitas yang melibatkan kerja otak dan gerak mata, Dengan demikian, kegiatan ini adalah sebuah kegiatan yang sangat kompleks karena melibatkan kerja fisik dan mental(Kamalasari, 2012).

Cara Meningkatkan Membaca Cepat yaitu menurut Turahmat (2010 : 42-43) ada beberapa cara yang bisa dilakukan untuk membaca dengan cepat yaitu: (1) Fokuslah pada kata kunci dan abaikan kata kata atau frasa penghubung. Contoh kata atau frasa penghubung: jadi, seperti yang diterangkan diatas, kemudian, oleh karena, sehubungan dengan hal tersebut, dll. (2) jangan membaca ulang informasi yang telah diketahui. Karena jumlah informasi yang ditransfer ke dalam memori jangka panjang terus bertambah, maka bagian bacaan yang dapat anda abaikan ketika membaca menjadi terus bertambah pula. Sehingga kecepatan membaca anda juga akan terus meningkat, (3) abaikan juga bahan bacaan yang tidak berhubungan dengan tujuan yang dicari, (4) tinggalkan dahulu bagian bacaan yang kelihatannya memusingkan dan tidak mudah dimengerti. Terus baca bagian lain dan baru kembali ke bagian tersebut apabila memang diperlukan. Karena seringkali kita baru memahami makna dari suatu bab setelah membaca bab selanjutnya. Dan bahan yang tidak kita ketahui tadi ternyata tidak ada hubungannya sama sekali dengan informasi keseluruhan bacaan. Sedangkan menurut Dalman (2017:43). Adapun hal-hal yang perlu dipelajari untuk meningkatkan kecepatan membaca sebagai berikut: (1) memahami hakikat membaca, (2) mengetahui cara mengukur kecepatan membaca, (3) mampu mengukur tingkat pemahaman terhadap bacaan, (4) mengetahui dan menerapkan metode dan teknik pengembangan 
kecepatan membaca, (5) mengetahui faktor-faktor secara tidak sadar menghambat kecepatan membaca baik faktor internal maupun faktor eksternal, (6) mengetahui bermacam-macam variasi kecepatan membaca sesuai dengan variasi tujuan membaca, (7) mampu memilih aspek tertentu yang dibutuhkan dalam bacaan sesuai dengan tujuan membaca, (8) menganggap kegiatan membaca sebagai kebutuhan, (9) selalu membaca pada berbagai jenis bacaan dengan rasa butuh yang sangat tinggi

Menurut Chistine Nuttal (dalam Dalman, 2017) standar kecepatan membaca untuk jenjang Sekolah Dasar adalah sebagai berikut.

Tabel 1. Kecepatan Efektif Membaca Jenjang SD

\begin{tabular}{cc}
\hline Kelas & Kecepatan Membaca \\
\hline Kelas I & $60-80$ kata per menit \\
Kelas II & $90-110$ kata per menit \\
Kelas III & $120-140$ kata per menit \\
Kelas IV & $150-160$ kata per menit \\
Kelas V & $170-180$ kata per menit \\
KelasVI & $190-250$ kata per menit \\
\hline
\end{tabular}

Kemampuan membaca adalah kecepatan membaca dan pemahaman isi maka dalam mengukur kemampuan membaca yang perlu diperhatikan adalah dua tersebut. Kecepatan membaca dapat diukur dengan rumus sebagai berikut:

$$
\text { jumlah KPM }=\frac{\text { jumlah kata yang dibaca }}{\text { jumlah detik untuk membaca }} \times 60
$$

Kajian penelitian yang relevan dengan penelitian yang berjudul keefektifan Cooperative Integrated Reading and Composition (CIRC) terhadap kemampuan membaca siswa kelas IV SD Negeri 1 Ngalian Wonosobo adalah penelitian yang berjudul "Model Cooperative Integrated Reading and Composition berpola Lesson Study meningkatkan kemampuan membaca dan menulis". Hasil penelitian yang dilakukan oleh I Made Sumantri pada bulan April hingga bulan November 2016. Data keterampilan membaca dan menulis siswa diperoleh dengan menggunakan tes keterampilan berbahasa. Hasil dari penelitian ini adalah (1) rata-rata keterampilan membaca siswa yang pada siklus I sebesar 67, pada siklus II peningkat mencapai 76, (2) rata-rata keterampilan menulis siswa yang pada siklus I sebesar 69, pada siklus II peningkat mencapai 79, (3) pada siklus 1 skor keterampilan membaca siswa dengan kategori "baik" dan "sangat baik" hanya mencapai 57,1 \%, pada siklus II meningkat menjadi 92,9\%, (4) pada siklus I, keterampilan menulis siswa dengan kategori "baik" dan "sangat baik" hanya 64,3\%, pada siklus II meningkat secara signifikan mencapai 92,9\%. Berdasarkan temuan-temuan tersebut, dapat disimpulkan bahwa penerapan Pembelajaran CIRC dengan pola lesson study mampu meningkatkan keterampilan membaca dan menulis siswa kelas IV SD N 3 Kampung Anyar Tahun Pelajaran 2016/2017.

Berdasarkan latar belakang masalah yang telah dikemukakan diatas, dapat mengidentifikasi masalah sebagai berikut : 1) Proses pembelajaran masih dominan menggunakan metode ceramah, sehingga siswa kurang tertarik, 2) Siswa kurang aktif dalam pembelajaran dan tidak memperhatikan guru saat pembelajaran, 3) Siswa masih kesulitan dalam membaca cepat, 4) Model pembelajaran yang digunakan dalam pembelajaran masih kurang menarik siswa.

Berdasarkan latar belakang dan identifikasi masalah yang ada maka peneliti melakukan pembatasan masalah. Permasalah yang dikaji adalah pada aspek kemampuan membaca cepat pada hasil belajar membaca siswa. Hal ini dilakukan agar permasalahan yang hendak diteliti lebih terfokus sehingga pembahasan lebih mendalam dan sistematis. Berdasarkan Identifikasi masalah dan pembatasan masalah di atas, maka dapat dirumuskan masalah sebagai berikut: apakah model pembelajaran Cooperative Integrated Reading and Composition (CIRC) efektif untuk meningkatkan kemampuan membaca siswa kelas IV SD Negeri 1 Ngalian Kabupaten Wonosobo?"

Tujuan Penelitian ini adalah untuk mengidentifikasi efektif atau tidaknya model pembelajaran Cooperative Integrated Reading and Composition (CIRC) terhadap kemampuan membaca siswa kelas IV SD Negeri 1 Ngalian Kabupaten Wonosobo.

\section{Metode}

Penelitian ini dilaksanakan di SD Negeri 1 Ngalian Kabupaten Wonosobo. Subjek penelitian adalah kemampuan membaca siswa kelas IV SD Negeri 1 Ngalian Kabupaten Wonosobo berjumlah 24 siswa 
dengan 10 siswa laki- laki dan 14 siswa perempuan.ata penelitian ini adalah data pelaksanaan yaitu proses pelaksanaan pembelajaran tema 4 berbagai pekerjaan dan data hasil yaitu data tentang hasil pelaksanaan pembelajaran tema 4 berbagai pekerjaan sub tema 1 jenis-jenis pekerjaan melalui model pembelajaran Cooperative Integrated Reading and Composition (CIRC)(Nazir, 2014).

Metode penelitian yang akan digunakan adalah metode penelitian eksperimen. Metode eksperimen adalah metode penelitian kuantitatif yang digunakan untuk mengetahui pengaruh variabel independen (treatmen/perlakuan) terhadap variabel dependen (hasil) dalam kondisi yang terkendali(Sugiyono, 2018). Teknik pengambilan data penelitian ini dengan menggunakan metode tes, metode wawancara dan metode dokumentasi.

Pada penelitian ini menggunakan bentuk desain penelitian Pre-Experimental Design. PreExperimental Design yang digunakan adalah one-group pretest-posttest design. Pada desain ini akan diberikan pretest sebelum diberikan perlakuan. Dengan demikian hasil perlakuan dapat diketahui lebih akurat, karena dapat membandingkan dengan keadaan sebelum diberi perlakuan. Teknik analisis data pada penelitian ini menggunakan uji normalitas dan uji t dengan uji satu pihak(Arikunto, 2010). Hasil perhitungan nilai siswa ini kemudian dibandingkan, yaitu antara hasil pretest dan posttest, kemudian dihitung rata-rata peningkatan nilai pada pretest dan posttest. Hasil ini akan memberikan gambaran mengenai rata-rata peningkatan kompetensi siswa dalam kemampuan membaca(Arikunto, 2013).

\section{Hasil dan Pembahasan}

Hasil penelitian di SD Negeri 1 Ngalian Kabupaten Wonosobo pada semester I tahun ajaran 2018/2019 pada kelas IV dengan jumlah 24 siswa. Kegiatan pembelajaran pada penelitian ini adalah menerapkan model pembelajaran Cooperative Integrated Reading and Composition (CIRC) terhadap kemampuan membaca siswa kelas IV SD Negeri 1 Ngalian Kabupaten Wonosobo.

Penelitian ini merupakan penelitian kuantitatif. Desain penelitian yang digunakan dalam penelitian ini adalah Pre Experimental Design dengan bentuk desain One-Group Pretest-Posttest Desain, untuk mengetahui keefektifan model pembelajaran Cooperative Integrated Reading and Composition (CIRC) terhadap kemampuan membaca siswa kelas IV SD Negeri 1 Ngalian Kabupaten Wonosobo pada tema 4 berbagai pekerjaan sub tema 1 jenis-jenis pekerjaan. Penelitian ini menggunakan teknik pretest-posttest. Pretest merupakan tes awal untuk mengetahui kemampuan awal siswa dan dilaksanakan sebelum siswa diberikan perlakuan oleh peneliti dengan menggunakan model pembelajaran Cooperative Integrated Reading and Composition (CIRC). Sedangkan posttest merupakan tes akhir untuk mengetahui kemampuan akhir siswa dan dilaksanakan setelah siswa diberikan perlakuan oleh peneliti dengan menggunakan model pembelajaran Cooperative Integrated Reading and Composition (CIRC).

Penelitian awal peneliti melakukan uji coba soal instrumen untuk menghitung validitas, realibilitas, daya pembeda, dan tingkat kesukaran soal di SD Negeri 2 Ngalian Kabupaten Wonosobo pada kelas V. Soal uji coba instrumen berupa soal pilihan ganda sebanyak 50 butir soal yang telah dikerjakan oleh 20 siswa. Setelah dilakukan analisis butir soal, peneliti melakukan penelitian di SD Negeri 1 Ngalian Kabupaten Wonosobo pada kelas IV. Peneliti melakukan pretest untuk mengetahui kemampuan awal siswa sebelum diberikan perlakuan oleh peneliti dengan menggunakan model pembelajaran Cooperative Integrated Reading and Composition (CIRC). Setelah diberikan perlakuan oleh peneliti, maka siswa diberikan posttest dengan tujuan untuk mengetahui kemampuan akhir siswa dengan menggunakan model pembelajaran Cooperative Integrated Reading and Composition (CIRC). Rekapitulasi hasil pretest dan posttest dapat dilihat pada tabel 02. di bawah ini.

Tabel 2. Data Hasil Pretest dan Posttest

\begin{tabular}{lcc}
\hline \multicolumn{1}{c}{ Keterangan } & Pretest & Posttest \\
\hline Nilai tertinggi & 80 & 97 \\
Nilai terendah & 23 & 60 \\
Rata-rata & 61,12 & 86,58 \\
Siswa tuntas & 8 & 22 \\
\hline
\end{tabular}

Sumber: Data Hasil Penelitian (2018)

Berdasarkan tabel 02 terdapat perbedaan antara nilai terendah, nilai tertinggi, nilai rata-rata, dan jumlah siswa yang tuntas pada pretest dan posttest. Nilai pretest diperoleh nilai terendah 23 Dan nitai tertinggi 80 sedangkan nilai posttest diperoleh nilai terendah 60 Dan nilai teringgi 97 Nilai rata-rata pada pretest atau sebelum diberikan perlakuan yaitu sebesar 61,12 Sedangkan nilai posttest atau setelah 
diberikan perlakuan menggunakan model pembelajaran Cooperative Integrated Reading and Composition (CIRC) didapatkan nilai sebesar 86,58. Yang selengkapnya dapat dilihat pada diagram 2.1

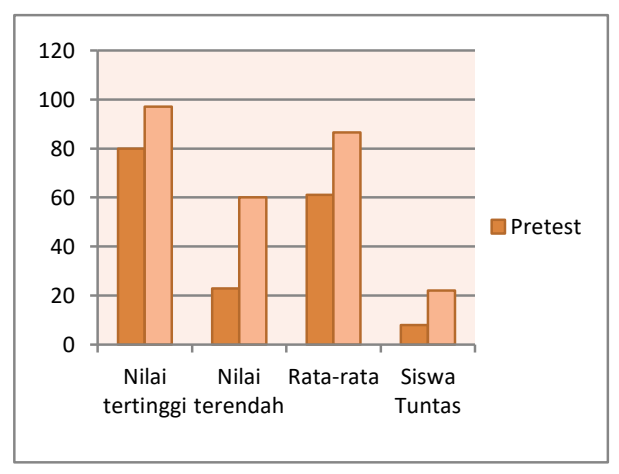

\section{Gambar 1. Hasil Pretest dan Posttest}

Berdasarkan diagram 01 menunjukan bahwa terdapat peningkatan antara nilai pretest sebelum diberikan perlakuan dengan nilai posttest yang sudah diberikan perlakuan dengan menggunakan model pembelajaran Cooperative Integrated Reading and Composition (CIRC). Hasil nilai pada penelitian ini yang dijadikan sebagai data akhir penelitian yaitu nilai posttest. Data yang diperoleh selanjutnya digunakan untuk menghitung uji normalitas dan uji t.

Tabel 3. Hasil Uji Normalitas Awal (Pretest)

\begin{tabular}{ccccc}
\hline \multicolumn{1}{c}{ Variabel } & N & Lo & Ltabel & Kesimpulan \\
\hline $\begin{array}{l}\text { Hasil nilai pretest } \\
\text { siswa }\end{array}$ & 24 & 0,0838 & 0,173 & Berdistribusi normal \\
\hline
\end{tabular}

Dari tabel 03, analisis hasil uji normalitas awal. Berdasarkan tabel 1.4. Perhitungan uji normalitas diperoleh harga mutlak selisih yang paling besar $\mathrm{L}_{0}=0,085$ dengan $\mathrm{n}=24$. Dan taraf nyata $\alpha=5 \%$ dari daftar nilai kritis $\mathrm{L}$ didapat $\mathrm{L}_{\text {tabel }}=0,173$. Karena $\mathrm{L}_{0}<\mathrm{L}_{\text {tabel }}$ yaitu $0,0838<0,173$ maka $\mathrm{L}_{0}$ diterima. Dapat disimpulkan bahwa data pretest siswa berasal dari populasi yang berdistribusi normal.

Tabel 4. Hasil Uji Normalitas Akhir (Posttest)

\begin{tabular}{ccccc}
\hline Variabel & $\mathbf{N}$ & Lo & $\mathbf{L}_{\text {tabel }}$ & Kesimpulan \\
\hline Hasil nilai pretest siswa & 24 & 0,1401 & 0,173 & Berdistribusi normal \\
\hline
\end{tabular}

Dari tabel 04, analisis hasil uji normalitas awal. Berdasarkan tabel 1.5. Perhitungan uji normalitas diperoleh harga mutlak selisih yang paling besar $\mathrm{L}_{0}=0,1401$ dengan $n=24$. Dan taraf nyata $\alpha=5 \%$ dari daftar nilai kritis $\mathrm{L}$ didapat $\mathrm{L}_{\text {tabel }}=0,173$. Karena $\mathrm{L}_{0}<\mathrm{L}_{\text {tabel }}$ yaitu $0,1401<0,173$ maka $\mathrm{L}_{0}$ diterima. Dapat disimpulkan bahwa data posttest siswa berasal dari populasi yang berdistribusi normal.

Berdasarkan perhitungan uji $\mathrm{t}$ diperoleh $t_{\text {hitung }}=17,68$. Selanjutnya $t_{\text {hitung }}$ tersebut dibandingkan dengan $t_{\text {tabel }}=2,021$ dengan $d b=24+24-1$ pada taraf signifikan $\alpha=5 \%$, sehingga diperoleh $t_{\text {hitung }}>t_{\text {tabel }}$ yaitu 17,68 > 2,021. Dengan demikian $\mathrm{H}_{0}$ ditolak dan $\mathrm{H}_{\mathrm{a}}$ diterima. Dapat disimpulkan bahwa ada perbedaan nilai pretest dan posttest, artinya ada perbedaan rata-rata pretest dan posttest sebelum menggunakan model pembelajaran Cooperative Integrated Reading and Composition (CIRC) dan setelah menggunakan model pembelajaran Cooperative Integrated Reading and Composition (CIRC).

\section{Kemampuan Membaca Cepat}

Kemampuan membaca cepat menunjukan kemampuan siswa dalam membaca teks bacaan dengan ketentuan waktu dan jumlah kata yang telah ditentukan(Tarigan, 2008). Rekapitulasi hasil membaca cepat siswa kelas IV SD Negeri 1 Ngalian Kabupaten Wonosobo dapat dilihat pada tabel 05 di bawah ini. 
Tabel 5. Data Hasil Membaca Cepat

\begin{tabular}{lcc}
\hline Keterangan & $\begin{array}{l}\text { Sebelum diberikan model } \\
\text { pembelajaran Cooperative } \\
\text { Integrated Reading and } \\
\text { Composition (CIRC) }\end{array}$ & $\begin{array}{l}\text { Sesudah diberikan model } \\
\text { pembelajaran Cooperative } \\
\text { Integrated Reading and } \\
\text { Composition (CIRC) }\end{array}$ \\
\hline Skor tertinggi & 162 & 179 \\
Skor terendah & 37 & 74 \\
Rata-rata & 118,62 & 158,41 \\
Siswa tuntas & 9 & 21 \\
\hline & & Sumber: Data Hasil Penelitian (2018)
\end{tabular}

Berdasarkan tabel 05 terdapat perbedaan antara skor membaca cepat siswa yang telah diberikan model pembelajaran Cooperative Integrated Reading and Composition (CIRC) dengan skor membaca cepat siswa yang sudah diberikan model pembelajaran Cooperative Integrated Reading and Composition (CIRC). Sebelum siswa diberikan perlakuan menggunakan model pembelajaran Cooperative Integrated Reading and Composition (CIRC) didapatkan skor membaca cepat tertinggi sebesar 162 kata per menit dan terendah sebesar 37 kata per menit. Sedangkan setelah diberikan perlakuan menggunakan model pembelajaran Cooperative Integrated Reading and Composition (CIRC) didapatkan skor membaca cepat tertinggi sebesar 179 kata per menit dan terendah sebesar 74 kata per menit.

Berdasarkan data pada Tabel 05, kemudian disajikan dalam bentuk diagram ketuntasan membaca cepat siswa kelas IV SD Negeri 1 Ngalian Kabupaten Wonosobo sebagai berikut:

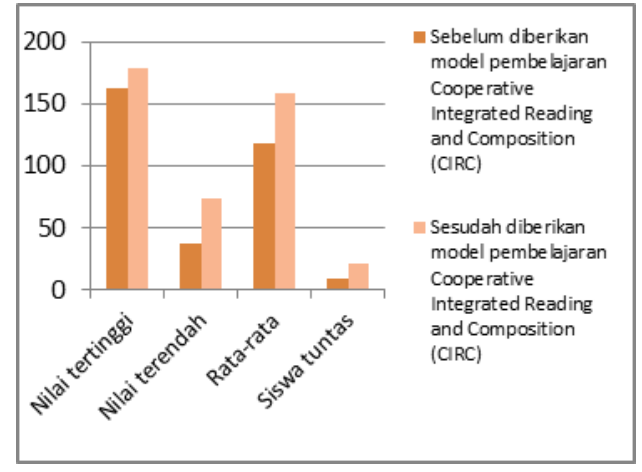

Gambar 2. Data Hasil Kemampuan Membaca Cepat

Dapat disimpulkan bahwa model pembelajaran Cooperative Integrated Reading and Composition (CIRC) efektif terhadap kemampuan membaca cepat siswa dalam tema 4 berbagai pekerjaan sub tema 1 jenis-jenis pekerjaan kelas IV SD Negeri 1 Ngalian Kabupaten Wonosobo.

Dari hasil penelitian ini berarti mendukung hasil penelitian sebelumnya bahwa model pembelajaran Cooperative Integrated Reading and Composition (CIRC) dapat meningkatkan kemampuan membaca siswa, bahkan dalam penelitian ini model pembelajaran Cooperative Integrated Reading and Composition (CIRC) tidak hanya meningkatkan kemampuan membaca siswa melainkan meningkatkan hasil belajar kognitif siswa. Seperti penelitian yang telah dilakukan oleh Ni Ketut Desia Tristiantari dan I Made Sumantri dalam Jurnal Pendidikan Indonesia dengan penelitian yang berjudul " Model Cooperative Integrated Reading and Composition berpola Lesson Study meningkatkan kemampuan membaca dan menulis" hasil penelitian tersebut menunjukan bahwa model pembelajaran Cooperative Integrated Reading and Composition (CIRC) dapat meningkatkan kemampuan membaca dan menulis siswa kelas IV SD N 3 Kampung Anyar Tahun Pelajaran 2016/2017 (Tristiantari,Ni Ketut Desia, 2016).

Dari penelitian sebelumnya sesuai dengan teori konstruktivisme dan teori kognitif. Dalam kaitannya dengan teori konstruktivisme dan teori kognitif siswa mengkonstruksi pengetahuannya secara mandiri dan sesuai dengan perkembangan kognitif siswa sehingga dalam pembelajaran hasil belajar kognitif siswa meningkat.

Menurut Piaget (dalam Rusman, 2017:119) belajar akan lebih berhasil apabila disesuaikan dengan tahap perkembangan kognitif siswa. Teori belajar kognitif menekankan kepada pentingnya proses 
internal, yaitu proses mental manusia. Sedangkan menurut Parwati, Ni Nyoman (2018:72) menyatakan bahwa Piaget membagi tahap-tahap perkembangan kognitif ini menjadi empat perkembangan kognitif, yaitu tahap sensorimotor (umur 0-2 tahun), tahap praoperasional (umur 2-7 tahun), tahap operasional konkret (umur 7-11), dan tahap operasional formal (umur 11-18 tahun). Sesuai dengan populasi penelitian yang digunakan yaitu siswa kelas IV yang memiliki rata-rata umur 10-11 tahun, oleh karena itu termasuk kedalam tahap operasional konkret. Pada tahap ini anak masih terbatas pada hal-hal yang konkret, maka anak masih membuhuthkan aktivitas belajar secara langsung. Menurut Rusman(2017:126) Anak akan menemui kesulitan untuk memecahkan masalah dengan hanya mengandalkan daya otaknya tanpa mencoba melakukan kegiatan (pengalaman langsung). Jadi teori kognitif ini berhubungan dengan teori konstruktivisme yang menganggap bahwa pengalaman belajar siswa secara mandiri akan memberikan pengalaman belajar yang lama.

Kelemahan model pembelajaran Cooperative Integrated Reading and Composition (CIRC) yaitu guru kesulitan dalam mengendalikan kelas karena setiap kelompok melakukan aktivitas secara aktif, selain itu dalam kegiatan diskusi kelompok rawan untuk saling mengganggu kelompok satu dengan kelompok lainnya saat berada bersebelahan, dan kelememahan lainnya pada penerapan model pembelajaran Cooperative Integrated Reading and Composition (CIRC) yaitu model pembelajaran ini hanya dapat digunakan untuk mata pelajaran yang menggunakan bahasa. Sehingga model pembelajaran ini sesuai untuk materi pembelajaran yang mengandung unsur kebahasaan dan kurang sesuai digunakan untuk mata pelajaran yang menggunakan prinsip menghitung seperti matematika (Isrokatun, 2018).

Kelebihan model pembelajaran Cooperative Integrated Reading and Composition (CIRC) yaitu meningkatkan keaktifan siswa dalam proses pembelajaran sehingga dalam pembelajaran semua siswa berperan aktif melalui diskusi kelompok, selain itu pembelajaran lebih menarik siswa sehingga hasil belajar siswa mengalami peningkatan, dan mendorong siswa untuk mengkonstruksi pengetahuannya sendiri melalui diskusi kelompok. Hal ini sesuai dengan teori kognitif yang dipelopori oleh Piaget dan teori konstruktivisme yang dipelopori oleh Lev S. Vygotsky yang mempunyai pandangan bahwa pengetahuan dan pemahamana diperoleh dari pengalaman sendiri(Tristiantari,Ni Ketut Desia, 2016).

Setelah melakukan penelitian di SD Negeri 1 Ngalian Kabupaten Wonosobo dengan menggunakan model pembelajaran Cooperative Integrated Reading and Composition (CIRC) terdapat karakteristik atau nilai lebih yang muncul yaitu siswa lebih cenderung suka bertanya ketika guru memberikan kesempatan siswa bertanya pada guru dan siswa lebih suka berdiskusi kelompok saat pembelajaran berlangsung.

\section{Simpulan dan Saran}

Berdasarkan hasil penelitian yang telah dilakukan di SD Negeri 1 Ngalian Kabupaten Wonosobo kelas IV tahun ajaran 2018/2019 dan pembahasan pada tema 4 berbagai pekerjaan sub tema 1 jenis-jenis pekerjaan maka dapat disimpulkan bahwa model pembelajaran Cooperative Integrated Reading and Composition (CIRC) efektif terhadap hasil belajar siswa dan kemampuan membaca cepat siswa. Dikarenakan (1) Rata-rata hasil belajar mengalami peningkatan yaitu sebesar 58,4\% sesudah siswa menggunakan model pembelajaran Cooperative Integrated Reading and Composition (CIRC). (2) Rata-rata kemampuan membaca cepat siswa mengalami peningkatan yaitu sebesar $50 \%$ setelah menggunakan model pembelajaran Cooperative Integrated Reading and Composition (CIRC). Adapun saran yang dapat diajukan berdasarkan hasil penelitian dan pembahsan adalah sebagai berikut: (1) kepada guru agar hasil penelitian ini dapat dijadikan acuan dan pengetahuan baru dalam menciptakan suasana pembelajaran yang aktif, inovatif khususnya model pembelajaran kooperatif Cooperative Integrated Reading and Composition (CIRC) sehingga dapat mengimplementasikannya di dalam kelas untuk meningkatkan kemampuan membaca siswa (3) kepada Kepala Sekolah agar hasil penelitian ini dapat dijadikan informasi yang berharga dalam proses pembelajaran untuk meningkatkan, serta untuk meningkatkan kemampuan membaca siswa (4) kepada peneliti lain agar memperhatikan kendala yang dialami dalam pelaksanaan model pembelajaran Cooperative Integrated Reading and Composition (CIRC) khususnya dalam meningkatkan kualitas membaca siswa untuk penyempurnaan penelitian yang akan dilaksanakan.

\section{Daftar Rujukan}

Arikunto, S. (2010). Prosedur Penelitian Suatu Pendekatan Praktik. Jakarta: PT Rineka Cipta. Arikunto, S. (2013). Dasar-Dasar Evaluasi Pendidikan. Jakarta: PT Budi Aksara.

Dalman. (2017). Keterampilan Membaca. Jakarta: PT Raja Grafindo Persada.

Huda, M. (2013). Model-Model Pengajaran dan Pembelajaran. Yogyakarta: Pustaka Pelajar. Isrokatun, dan R. A. (2018). Model-Model Pembelajaran Matematika. Jakarta: PT Budi Aksara. 
Kamalasari, V. (2012). Latihan Membaca Cepat Sebagai Upaya Meningkatkan Kemampuan Membaca Cepat dan Pemahaman Bacaan. Basastra, 1(1).

Nazir, M. (2014). Metode Penelitian. Bogor: Ghalia Indonesia.

Parwati, Ni Nyoman, I. P. P. S. (2018). Belajar dan Pembelajaran. Depok: PT Raja Grafindo Persada.

Rahim, F. (2005). Pengajaran Membaca di Sekolah Dasar. Jakarta: PT Kharisma Putra Utama.

Rusman. (2017). Belajar dan Pembelajaran Berorientasi Standar Proses Pendidikan. Jakarta: PT Kharisma Putra Utama.

Shoimin, A. (2015). 68 Model Pembelajaran Inovatif dalam Kurikulum 2013. Yogyakarta: Ar-Ruzz Media.

Sudjana. (2005). Metode Statistika. Bandung: Tarsito Bandung.

Sugiyono. (2018). Metode Penelitian Kuantitatif. Bandung: Alfabeta.

Tarigan, H. G. (2008). Membaca Sebagai Ketempilan Membaca. Bandung: Angkasa Bandung.

Tristiantari,Ni Ketut Desia, I. M. S. (2016). Model Pembelajaran Cooperatif Integrated Reading Composition Berpola Lesson Study Meningkatkan Keteramplan Membaca Dan Menulis. Jurnal Pendidikan Indonesia, 5(2).

Turahmat. (2010). Teknik-Teknik Membaca. Semarang: Pustaka Najwa. 